\title{
Considerações acerca dos primeiros periódicos científicos brasileiros
}

\author{
Maria Helena Freitas \\ Mestre em história da ciência pela PUC-SP. \\ E-mail: mhelena@prt15.gov.br
}

\section{Resumo}

Analisa os periódicos da área de ciências publicados no Brasil no início do século XIX, entendendo-os como um dos pilares da institucionalização da ciência no país. São avaliados, principalmente, O Patriota, Jornal Litterario, Politico, Mercantil \&c. do Rio de Janeiro, o primeiro periódico dedicado às ciências e às artes no país, publicado de 1813 a 1814, assim como os Annaes Fluminenses de Sciencias, Artes e Litteratura, Publicados por huma Sociedade Philo-Technica no Rio de Janeiro (1822) e o Jornal Scientifico, Economico e Literario (1826), principais comunicadores das artes e das ciências no Brasil até a década de 1830, a fim de considerar as condições de surgimento e as características dessas publicações.

\section{Palavras-chave}

Brasil - história da ciência. Periódicos científicos - história. Comunicação científica - Brasil.

\section{Considerations about the first scientific journals in Brazil}

\begin{abstract}
This article analyzes scientific journals publishied in Brazil at the beginning of $19^{\text {th }}$ century, understanding them as one of them pillars of the institutionalization of science in the Country. It analyzes, more specifically, O Patriota, Jornal Litterario, Politico, Mercantil \&c. do Rio de Janeiro, the first journal dedicated to the sciences and arts in Brazil, published during 1813-1814, as well as the Annaes Fluminenses de Sciencias, Artes e Litteratura, Publicados por huma Sociedade Philo-Technica no Rio de Janeiro (1822) and the Jornal Scientifico, Economico e Literario (1826), journals that appeared before 1830, in order to evaluate the conditions of sprouting and the characteristics of these publications.
\end{abstract}

\section{Keywords}

Brasil - History of science. Scientific journals - history. Scientific communication - Brasil.

\section{INTRODUÇÃO}

Antes do surgimento dos periódicos científicos, desde a invenção da imprensa até o século XVII, as notícias sobre a ciência, as técnicas variadas e as invenções eram veiculadas em folhetins, em volantes e em jornais cotidianos. Até essa época, o conhecimento mais especializado era comunicado por correspondências realizadas entre os cientistas ou enviadas às agremiações científicas. Essas correspondências vão originar, no século XVII, as publicações científicas, as quais, ao contrário das anteriores correspondências entre os estudiosos, são voltadas a um público mais amplo, embora específico.

Tais modificações nos modos de fazer e relatar ciência somente foram possibilitadas pelo surgimento de uma nova concepção de saber e pela crença na idéia de progresso humano através desse conhecimento.

Os periódicos foram, desde seus primórdios, importantes canais de publicação de notícias científicas. No século XIX, expandiram-se e especializaram-se, vindo a realizar importantes funções no mundo da ciência. Ao publicarem textos, os estudiosos registram o conhecimento (oficial e público), legitimam disciplinas e campos de estudos, veiculam a comunicação entre os cientistas e propiciam ao cientista o reconhecimento público pela prioridade da teoria ou da descoberta.

Além de fonte privilegiada da história da ciência, o periódico científico pode ser considerado um espaço institucional da ciência, pois se insere dentro do universo das realizações e comunicação das atividades científicas. Figueirôa (2000, p. 165) define espaços institucionais

não apenas no sentido mais restrito de instituições científicas, tais como museus e institutos de pesquisa, mas como o conjunto de todas as possibilidades de realização e divulgação de atividades científicas (conforme o sentido da época). (...) Assim, um museu e uma revista, por exemplo, são igualmente espaços institucionais, embora apresentem características diversas e específicas*.

\footnotetext{
* Grifo da autora.
} 
Assim, a compreensão dos caminhos da comunicação científica no Brasil acrescenta mais uma faceta à história da nossa ciência.

O periodismo* surge no Brasil no século XIX, quando são afrouxadas as amarras da política colonial portuguesa, com a inédita e instantânea transformação brasileira de colônia à sede da Corte, em 1808. Embora as condições artificialmente criadas tivessem o intuito de transplantar as instituições portuguesas para o Brasil, servindo às necessidades da Corte portuguesa, acabaram por iniciar a institucionalização da cultura brasileira e por estimular os brasileiros a elaborar uma identidade nacional e organizarem-se como nação.

A Corte portuguesa, além de permitir a existência da imprensa no país, criou numerosas instituições científicas que iniciaram a prática e o estudo das ciências, abrigaram coleções de espécimes nacionais e serviram de referência às atividades da medicina, da engenharia, da navegação e da arte militar. Como comenta Oliveira (1997), ao mesmo tempo que torna a imprensa livre, estabelece a censura, bem de acordo com o obscurantismo do passado português.

Como na maioria do países euro-americanos, a divulgação e a comunicação da ciência no Brasil é iniciada no século XIX em jornais cotidianos, não especializados e voltados ao grande público.

O primeiro periódico impresso no Brasil, a Gazeta do Rio de Janeiro, realizou esse papel de divulgador dos assuntos científicos, noticiando a produção de obras, a realização de cursos, a produção e venda de livros e textos científicos. Além das notícias e alusões, o periódico chegou a publicar memórias científicas.

Depois da Gazeta do Rio de Janeiro, surge a Idade d'Ouro do Brasil, na Bahia, assim como as revistas As Variedades ou Ensaios de Literatura, o primeiro jornal literário brasileiro, também na Bahia, e O Patriota, Jornal Litterario, Politico, Mercantil Ëc. do Rio de Janeiro, o primeiro periódico especialmente dedicado às ciências e às artes no país.

Foi objetivo desta pesquisa, mediante o estudo dos primórdios do periodismo científico brasileiro, propiciar um conhecimento maior do fazer científico no Brasil no início do século XIX e analisar, mais detidamente, a construção histórica da comunicação científica no país.

O estudo partiu de levantamentos realizados nos seguintes catálogos e base de dados nacionais: o Catálogo

* Leia-se a imprensa em geral. A tipografia foi absolutamente proibida no Brasil até 1808 .
Coletivo Nacional (CCN) do Instituto Brasileiro de Informação em Ciência e Tecnologia (Ibict), a Biblioteca Nacional e a Lusodata (do Grupo de História e Teoria da Ciência - DRCC/IFGW/Unicamp).

O exame dos periódicos foi realizado em diferentes instituições que possuíam o material selecionado em seus acervos: os periódicos disponíveis na forma de microfilmes (A Estrela Brasileira, O Bem da Ordem, $\mathrm{O}$ Espelho, A Malagueta, a Abelha do Itacolomy, O Beija-Flor, o Jornal Scientifico..., a Revista Medica Brasileira, os Annaes de Medicina Brasiliense, a Revista Medica Fluminense, O Brazil Medico, o Semanario de Saude Publica... e os Annaes Fluminenses de Sciencias, Artes e Literatura, entre outros) foram examinados na Biblioteca Nacional (Rio de Janeiro/RJ), na Biblioteca do Instituto Histórico e Geográfico Brasileiro (Rio de Janeiro/RJ), e no Arquivo Histórico Edgar Leuenroth da Unicamp (Campinas/SP); O Patriota, na forma digital, foi examinado no Centro Simão Matias (Cesima), da Pontifícia Universidade Católica de São Paulo (PUC/SP) (São Paulo/SP); e na forma impressa foram examinados outros periódicos $(O$ Tamoyo, a Revista do Instituto Polytechnico Brasileiro, $\mathrm{O}$ Auxiliador da Industria Nacional, e a Revista do Instituto Historico e Geographico do Brazil) na Biblioteca do Instituto de Filosofia e Ciências Humanas da Unicamp (Campinas/ SP) e na Biblioteca do Museu Histórico Nacional (Rio de Janeiro/RJ).

O estudo foi limitado ao Brasil Reino e 1o Império, a partir da verificação de que foi nesses contextos que se fundaram os primeiros periódicos científicos no país.

\section{A IMPRESSÃO RÉGIA E O INÍCIO DA PUBLICAÇÃO DE CIÊNCIA NO BRASIL}

Quando dom João VI, fugindo de Napoleão Bonaparte, aportou na Bahia, o país não contava com uma população de mais de quatro milhões de pessoas, enredadas nas lavouras de cana, algodão e tabaco ou embrenhadas pelos sertões em meio ao gado, em busca de ouro e ou de índios. Como afirma Machado (2003, p.19), em 1800

o país tinha 3.660.000 habitantes, dos quais uma minoria sabia ler e escrever. (...) As cidades vegetavam, alheias a qualquer manifestação intelectual. (...) Não é de estranhar que em todo o país não houvesse meia dúzia de livrarias.

Nos primeiros anos do século XIX, podia-se encontrar no Rio de Janeiro três livrarias, onde se vendiam os mais diversos produtos, como fumo, chás, louças, artigos em geral e também livros. Pois vender somente livros em um país de analfabetos deveria ser bastante temerário. 
Além disso, sendo a atividade tipográfica ainda proibida, o ramo livreiro teria de esperar alguns anos para se desenvolver no país.

Somente após a chegada do rei as instituições educacionais, científicas, políticas e comerciais de toda ordem foram autorizadas a existir. Inclui-se, nessa liberação, a tipografia. A política cultural imposta pela Coroa portuguesa no Brasil nos três séculos anteriores produziu um círculo vicioso que somente pôde ser rompido à beira do século XX. A falta de escolas não produzia público leitor; a falta de tipografias não produzia material de leitura ou estudo, e a falta de agremiações científicas e cursos superiores dificultava a existência de produtores e consumidores de ciência. Como explicam Alfonso-Goldfarb, Ferraz e Figueirôa (1997, p.226),

sem público formado para a leitura e sem livros para ler, a difusão do saber no século XVIII surge como uma serpente que morde a própria cauda. E esforços para romper esse círculo vicioso são, no século XVIII, quase inexistentes.

Como o governo necessitava imprimir seus atos e decretos, a fundação da tipografia real foi uma das primeiras ações da Corte no Brasil. E, se o prelo veio atender à demanda do governo real, acabou imprimindo a palavra escrita de uma nova identidade cultural.

A Impressão Régia foi, até 1821, a maior tipografia brasileira, tanto por monopólio da publicação dos atos oficiais, quanto pela existência da censura oficial, que afastava do ramo muito possíveis interessados. Imprimia um pouco de tudo: atos institucionais - leis, alvarás, decretos, cartas régias, editais - apólices e ações do Banco do Brasil, passaportes, guias de passagens, papéis timbrados, guias, recibos, livros de escrituração, livros, folhetos, folhas avulsas, listas de navios, regimentos de preços de medicamentos, efemérides náuticas, relações de despachos, folhinhas, almanaques, calendários eclesiáticos, coletâneas de legislação, balanços e balancetes (CAMARGO, 1993, p.xii-xiii). Segundo esses autores, a Impressão Régia foi uma editora excelente, que

publicou dezenas de livros de real valor cultural, fez conhecer os poetas famosos, em moda em Portugal, imprimiu os versos dos nossos, lançou o romance e a novela no Brasil, resolveu o problema do livro didático para o ensino superior inaugurado no Rio de Janeiro e cumpriu sua missão principal quanto à legislação (MORAES, 1993, p.xxx).

A transferência da Corte marcou, em resumo, o início de uma política que, como observam Alfonso-Goldfarb,
Ferraz e Figueirôa (1997, p. 228), mesmo tímida e limitada, contribuiu para a criação de um público para assimilar, traduzir e produzir textos de conteúdo científico.

As publicações periódicas da Impressão Régia são inauguradas com o jornal a Gazeta do Rio de Janeiro, em 1808, que funcionava, praticamente, como um diário oficial.

Ao lado dos documentos oficiais, a Impressão Régia publicou muitos outros textos. As duas primeiras publicações não oficiais noticiadas pela Gazeta do Rio de Janeiro, em 10 de setembro de 1808, foram a Memoria historica da invasão dos franceses, de dom José Caetano da Silva Coutinho, e as Observações sobre o commercio franco, de José da Silva Lisboa.

Também já em 1808 a Impressão Régia imprime as Reflexões sobre alguns dos meios propostos por mais conducentes para melhorar o clima da cidade do Rio de Janeiro, do médico da Real Câmara Manoel Vieira da Silva. É o primeiro trabalho médico (e de saúde pública) impresso no Brasil. Encomendado pelo príncipe regente, descreve a situação geográfica do Rio de Janeiro, e ainda

...mostra os danos causados à saúde pública pelos pântanos e aconselha que sejam aterrados. Condena o hábito de se enterrarem os mortos nas igrejas. Aconselha que se aumente e melhore o cemitério da Misericórdia e que se construa um lazareto onde os escravos importados fiquem de quarentena. Critica o desasseio dos açougues, as condições precárias do matadouro, a falta de bons medicamentos e a venda indiscriminada dos mesmos (CAMARGO; MORAES, 1993, v.1.p.12).

Moraes (1993) afirma que a Impressão Régia teve importante papel na comunicação das ciências e como auxiliador do ensino superior. Para prover os alunos das novas escolas, a Impressão Régia começa a publicar manuais científicos: Elementos de Geometria e o Tratado de Trigonometria, de Legendre (1809); o Tratado Elementar D'Arithmetica, de Lacroix (1810), Tratado Elementar de Physica, de Haüy (1810), Elementos d'Algebra, tanto de Euler quanto de Lacroix (1811) e vários outros nos anos subseqüentes. Os livros eram de consagrados autores da época e foram traduzidos pelos lentes das novas escolas.

E foi a Impressão Régia que imprimiu o primeiro periódico destinado a publicar textos de ciência, entre história e literatura, no Brasil, que foi a revista $O$ Patriota, Jornal Litterario, Politico, Mercantil Ëc. do Rio de Janeiro, editada de 1813 a 1814. 
OS JORNAIS LITERÁRIOS: PRIMEIROS PERIÓDICOS A PUBLICAR CIÊNCIA NO BRASIL

Da chegada da Corte portuguesa até a década de 30, momento de grande transformação política e cultural do Brasil, poucos periódicos a comunicar as letras e as artes surgiram no cenário nacional, e os que surgiram tiveram vida breve. Essa ausência pode ser explicada pelo fato de que toda a estrutura administrativa, educacional e científica do país estava ainda sendo criada, e muitas vezes, apenas por decretos oficiais. Muitas instituições foram assim fundadas e, logo depois, abandonadas pelo governo.

Jornais de cunho político o Brasil teve inúmeros. Conseguindo publicar somente um número ou durante anos, não faltaram publicações dessa natureza. Mas, quanto à comunicação das letras e das artes ${ }^{*}$, tem-se pouco a contar: O Patriota, Jornal Litterario, Politico, Mercantil, Ec. do Rio de Janeiro (Rio de Janeiro, 1813-1814), os Annaes Fluminenses de Sciencias, Artes e Litteratura, Publicados por huma Sociedade Philo-Technica no Rio de Janeiro (Rio de Janeiro, 1822), o Jornal Scientifico, Economico e Literario (Rio de Janeiro, 1826), O Propagador das Sciencias Medicas (Rio de Janeiro, 1827) e O Beija-Flor: Annaes Brasileiros de Sciencia, Politica, Litteratura (Rio de Janeiro, 1830-1831). Esses foram os principais comunicadores das artes e das ciências no reino e $1^{\circ}$ Império do Brasil.

Na verdade, essa questão gira em torno do termo utilizado para definir, naquela época, o que hoje denominamos "periódico científico". Era comum a utilização de denominações como "revista literária", "jornal de cultura", jornal de ciências e artes" e, principalmente, "jornal literário". A denominação utilizada estava totalmente de acordo com a estrutura do próprio conhecimento e cultura científica da época, mais miscelânica do que especializada, como é atualmente. Assim, em uma leitura histórica, parece complicado visualizar os periódicos científicos brasileiros do início do século XIX.

Os "jornais literários" traziam artigos técnico-científicos redigidos na linguagem própria da ciência, com várias observações sobre experimentos realizados, gráficos, tabelas e fórmulas. Traziam também vários artigos traduzidos de outros periódicos estrangeiros, comentários de outras obras e resumos de textos.

\footnotetext{
"Pode-se entender como "artes" o que hoje entendemos como "técnicas", desde a agricultura até desenho e pintura.
}

Alguns outros periódicos breves chegavam a publicar notas de fatos científicos, mas não se pode chamá-los de jornais voltados às ciências e às letras. Pretendiam-se políticos e críticos sociais, mas, às vezes, de forma erudita, faziam comentários sobre obras publicadas nas áreas de história, geografia e economia política. Publicaram poucos textos e correspondências a respeito de outras áreas científicas. Assim foram, como se pode atestar nos próprios periódicos, $\mathrm{O}$ Espelho, publicado no Rio de Janeiro em 1821, A Malagueta, publicada também no Rio de Janeiro, de 1821 a 1832, e a Abelha do Itacolomy, publicada em Ouro Preto, de 1824 a 1825.

\section{O PATRIOTA}

O Patriota foi por muitos considerado a primeira "revista" a ser impressa no Brasil. Esses estudiosos desconsideraram a publicação d'As Variedades ou Ensaios de Literatura, realizada na Bahia em 1812. As Variedades divulgava "discursos, extratos de história antiga e moderna, viagens, trechos de autores clássicos, anedotas, etc.” (SODRÉ, 1999, p.30). Vianna (1945) comenta que As Variedades é por muitos desconhecida, tendo-se veiculado largamente que $O$ Patriota foi a primeira revista brasileira. As Variedades teve somente dois números, em fevereiro e em julho de 1812 . Sodré (1999, p. 30) chamou-a de "ensaio frustrado de periodismo de cultura".

As Variedades era editada na Bahia por Silva Serva, também proprietário da Gazeta da Bahia e da Idade d'Ouro do Brasil. Segundo Rizzini (1988, p. 336), “a empresa baqueou na indiferença pública: o produto das assinaturas não dava para o pagamento da impressão". Por essa mesma razão, inúmeros periódicos não conseguiram sobreviver no país.

Afirma Sodré (1999, p. 30) que O Patriota era "do mesmo gênero" que As Variedades. Já Rizzini (1988, p. 336) chama O Patriota de "a melhor publicação literária, não apenas da Colónia, mas do Reino e da Regência."

Nunes (1991, p. 127, nota 1), ao analisar o Jornal de Coimbra, um dos periódicos portugueses "de divulgação de conhecimentos científicos e úteis" do século XIX, define periódicos científicos como o material impresso que se ocupa da divulgação de temas científicos e técnicos, com finalidades tanto recreativas quanto instrutivas, incluindo-se aí textos da categoria literária e moral."

Seguindo a definição de Nunes (1991) e analisando os textos publicados, pode-se afirmar que Sodré (1999) e Rizzini (1988) foram demasiadamente econômicos em relação às qualidades científicas d'O Patriota. 
Outros estudiosos, ao considerar O Patriota, seguem a compreensão de Nunes (1991) acerca do periodismo científico daquele momento. Alfonso-Goldfarb, Ferraz e Figueirôa (1997, p.228) afirmam que O Patriota não só publicava ciência, mas também difundia novos métodos e técnicas científicas:

Interessa-nos aqui particularmente $O$ Patriota, Jornal litterario, politico, mercantil, etc. que apareceu de 1813 a 1814. Embora efêmero (18 números), este jornal aborda um largo leque de temas diversificados. As técnicas de navegação, a mineralogia, a botânica, a química, a medicina, estão ao lado da literatura, da história e da geografia. Os artigos são tanto traduções quanto textos originais que propõem novos métodos e novas técnicas.

Também assim afirma Fonseca $(1999$, p. 83), para a qual O Patriota foi "o primeiro periódico a dedicar-se especialmente à divulgação das ciências e das letras, entendidas como instrumento desencadeador de progresso".

Vianna (1945, p. 82), ao estudar a publicação de textos da área de agricultura no Brasil, afirma que

O Patriota, "Jornal Literário, Político, Mercantil, etc.", foi, certamente, primeiro a fazê-lo, efetuando-o, aliás, do modo mais brilhante, pela excelência das diversas memórias contidas em seus três volumes....

O Patriota foi fundado e dirigido por Manuel Ferreira de Araújo Guimarães (1777-1838), na época redator da Gazeta do Rio de Janeiro e um dos primeiros lentes nomeados para a Real Academia Militar". Como expõe Rizzini (1988, p. 337):

Ferreira de Araújo foi um dos mais perseverantes lidadores da nossa incipiente literatura jornalística. Baiano, professor da Academia de Marinha de Lisboa, onde estudara, pensionado pelo governo, $1^{\mathrm{O}}$ tenente, matemático e latinista, regressou ao Salvador em 1805. Passando ao Rio, obteve transferência, ajudado de Linhares, para o corpo de engenheiros. Leccionou nas Academia de Marinha e Militar e chegou ao posto de Brigadeiro. Elaborou e traduziu diversas obras sobre a sua especialidade, versejou, meteu-se na política, foi deputado na $1^{\text {a }}$ Constituinte e mourejou sem descanso na imprensa.

\footnotetext{
* No decorrer do texto será utilizada a abreviação de seu nome para Ferreira de Araújo, como o próprio o fazia, assim como outros estudiosos também o denominaram.
}

Embora Martins (1978, p. 36-37) afirme que Ferreira de Araújo era dado a "epicédios, epitalâmios e elegias" à Corte real, tendo publicado poesias de "cortesanice congratulatória ou alimentar", também comenta que o mesmo publicou os Elementos de Astronomia, citando Abraão de Morais (s.d., p.119), o qual afirma não conter nada original na obra, mas que "a leitura dos quatro livros de que se compõe o compêndio nos revela que o autor estava perfeitamente familiarizado com os progressos da astronomia até sua época". Questão é que o próprio Ferreira de Araújo informa que sua obra tratava-se de um compêndio, como explicam Camargo e Moraes (1993, p. 134). Assim sendo, não era finalidade do autor ser original. Sua finalidade era oferecer uma obra didática aos alunos da Academia Real Militar, conforme consta na própria capa da obra.

Não somente o fundador d'O Patriota, assim como os colaboradores do periódico foram importantes estudiosos brasileiros, mas todos formados fora do país, e a maioria na Universidade de Coimbra. Como expõe Carvalho (1996, p. 33),

a elite brasileira, sobretudo na primeira metade do século XIX, teve treinamento em Coimbra, concentrado na formação jurídica, e foi, em sua grande maioria, parte do funcionalismo público, sobretudo da magistratura e do exército.

Além disso, mostraram-se ávidos por desenvolver uma ciência voltada aos interesses brasileiros.

No primeiro número d'O Patriota, Ferreira de Araújo (1813, p. iii-iv) explica a importância de se comunicar ciência e, por conseguinte, a importância do próprio periódico, com vistas ao progresso e a realizações maiores:

He huma verdade, conhecida ainda pelos mais instruidos, que sem a prodigiosa invenção das letras, haverão sido muito lentos os progressos nas Sciencias, e nas Artes. Por ellas o Europeu transmitte ao seu antipoda as suas descobertas, e as mais doces sensações da nossa alma, os nossos mesmos suspiros (para fallar com Pope) voão do pólo á India.” (...) Mas instruidos pela physica de que os raios do sol, que dispersos aquecem apenas os corpos duros, juntos em hum fóco derretem os mais densos metaes, os sabios se proposerão a communicar-se reciprocamente suas luzes, para que da união d'ellas resultasse aquelle intenso calor, que vencesse a frieza da priguiça, e a dureza da ignorancia. As suas primeiras Obras abrirão o caminho a outras mais perfeitas. 
Conforme Fonseca (1999, p. 84),

a importância das minas e a ciência prática do laboratório químico ampliavam o conjunto dos conhecimentos científicos divulgados pelo periódico, correspondendo plenamente aos objetivos propostos, ou seja, a difusão das "luzes" para o benefício e o progresso da sociedade.

A predileção pelos textos nacionais foi uma constante nas edições do periódico. A maioria dos textos versou sobre questões nacionais, sendo a autoria, quase que totalmente, de autores nacionais. Nas páginas d'O Patriota, pode-se ver, claramente, a partir das variadas vezes em que são usados os termos progresso, luzes, desenvolvimento, interesse do Brasil, felicidade pública, o sentimento geral dos estudiosos brasileiros em compartilhar o conhecimento das ciências com vistas ao progresso e desenvolvimento do país, totalmente imbuídos de um sentimento patriótico. Ferreira de Araújo, em seu editorial, deixava claro essa predileção: "Tenho curado de misturar noticias nacionaes com estrangeiras, preferindo as primeiras"(GUIMARÃES, 1813 , p. viii.) Para Fonseca (1999, p. 83), essa predileção tinha um significado bastante preciso:

Os estudiosos da ciência procuravam, por meio de seus trabalhos e do exercício de suas funções, apontar a relevância dos estudos práticos sobre a natureza e sobre as potencialidades das terras americanas, e a difusão de obras preconizadoras da ciência moderna.

Estudar a natureza brasileira vai ao encontro dos anseios patrióticos e de busca da identidade dos intelectuais da época. Fonseca (1999) afirma que os textos do botânico Manuel Arruda da Câmara e do médico Jacinto José da Silva Quintão, n'O Patriota, destacaram-se na busca da afirmação da natureza brasileira, como se vê no seguinte texto de Quintão (1813, p. 12):

...porém eu animado, e esperançado nos desejos, que tenho de ser útil a vós e a Estado, vou participar-vos as verdadeiras luzes, que tenho adquirido sobre este objecto, dando-vos o methodo de a propagardes para que sejais util a vós mesmos, e promovais a felicidade da minha e vossa Patria, e na Nação inteira, e de ter eu a satisfação de ver aceito, e posto em pratica o meu trabalho pelos meus Patricios zelosos, e agradecidos ás riquezas da omnipotente Natureza, julgando-me ser o primeiro que com tanta individuação vos faça conhecer a Cochonilha, e a sua propagação.

Note-se que até o título do artigo demonstra o sentimento patriótico do autor: "Memoria sobre a Cochonilha e o methodo de a propagar, offerecida aos Lavradores Brazileiros, por hum patriota zeloso, e amante da felicidade publica" (QUINTÃO, 1813, p.11).

O mesmo se pode dizer de Borges de Barros, em textos também publicados n'O Patriota:

Seria do maior interesse que tão digno desejo de conhecer as produções do mais rico dos paizes se propague, e que não deixemos ignorados, e nos privemos a nós e ao resto do mundo das vantagens e riquezas de que somos possuidores (BARROS, 1813, Memória..., p. 49).

E em fim, que he de nosso interesse se fazer renascer as plantações e fabricas do anil, e po-las em tal pé que o nossa possa sustentar a concorrencia no mercado, livrando-nos da vergonha e do desprezo, em que se tem quantos generos sahem das nossas fabricas Brazileiras, o que he tanto mais facil, quanto pecão, não na qualidade da materia primeira, mas dos mal entendidos e peior executados processos, e que felizmente sobre cada hum d'elles ha muito escritos, que cada dia hirão vulgarizando, e desarreigando a má rotina; as luzes espalhão-se no mundo para todos, cumprese aproveita-las (BARROS, 1813, Noções..., p.43).

Domingos Borges de Barros, depois Visconde da Pedra Branca, foi o maior colaborador d'O Patriota. Filho de família abastada, estudou no Colégio dos Nobres, tendose formado em filosofia natural pela Universidade de Coimbra. Também estudou ciências naturais em Paris. Retornando à Bahia em 1811, foi logo depois nomeado para diretor do Jardim Botânico de Salvador e professor do Curso de Agricultura que neste se formou (RIZZINI, 1988, p. 337; VIANNA, 1945, p. 147-148).

Borges de Barros era um grande noticiador do que se passava na Europa, além de ter traduzido muitos textos célebres n'O Patriota. Dos 18 fascículos publicados do jornal, apenas cinco não levaram textos de sua autoria.

Outros importantes colaboradores do periódico foram Jacinto José da Silva Quintão, José Bonifácio de Andrade e Silva e Silvestre Pinheiro Ferreira. O Patriota publicou também texto de Manuel Arruda da Câmara, grande naturalista brasileiro.

Ferraz (1997, p. 205-207) chama a atenção para o texto de Silvestre Pinheiro Ferreira, Memoria sobre hum novo princípio da Theorica do Calórico, publicado n'O Patriota em 1813,

na qual o autor vai contestar algumas das idéias expostas por Lavoisier, sendo mesmo implacável com 
o sábio francês. (...) Ferreira pensa que Lavoisier teria se contentado em 'aventurar esta simples idéia, sem contudo the dar mais valor do que o de uma hypothese' por falta de tempo para deter-se numa explicação mais adequada."

A concepção utilitarista da ciência é também regra nos textos não somente d'O Patriota..., mas também dos outros periódicos da época. Ferreira de Araújo, no editorial do primeiro número do periódico, já antecipava o teor dos textos que se sucederam nesse sentido:

Deste genero hei dado algumas que são da mais decidida utilidade; vindo desta arte a abranger neste periodico escritos, que lhe escapavão pela sua extensão (GUIMARÃES, 1813, p. viii).

O Patriota traz inúmeros artigos sobre técnicas variadas de fabricação, intituladas "memórias" ou "notícias". Esses textos eram traduções de outros artigos, resumos, resenhas, apanhados detalhados de assuntos os mais variados, desde botânica, artes, agricultura e hidráulica, até tradução de textos literários, como uma tradução do Livro 2ำ das Geórgicas, de Virgílio.

O Patriota, impresso pela Impressão Régia, teve 18 números. Publicado mensalmente em 1813, passou a bimensal em 1814, quando se findou. Como pudemos averiguar, tinha em média 120 páginas no primeiro ano e 100 no segundo, e publicava todos os assuntos, no estilo do Journal de Sçavans. ** Publicava também literatura, razão talvez de ter ganho a classificação de jornal literário de vários estudiosos da imprensa no Brasil. Esses mesmos estudiosos não atentaram para a questão, já comentada, de que as publicações comunicadoras das ciências e das técnicas eram, na época, nomeadas de "jornais literários", entre outras denominações, mas com um significado totalmente diverso de nossa compreensão atual.

Os 287 textos publicados n'O Patriota dividem-se nas seguintes áreas, classificados pelo próprio periódico: Artes $^{* * *}$ (9 textos); Botânica e Agricultura (15); Química

\footnotetext{
* O texto analisado pela autora foi publicado n'O Patriota, 2. subscr., n. 1, p. 3-11, jul. 1813.

** O Journal de Sçavans foi o primeiro periódico francês a divulgar a ciência, tendo sido criado por Dennis de Sallo, em 1665.

**** Para se exemplificar de quais artes se tratavam, seguem alguns títulos dos artigos publicados: Branqueação da cera; Memoria sobre hum alambique existente no Laboratorio do Excellentíssimo Antonio de Araujo, que contém as invenções mais modernas praticadas na Escossia, e ao qual se fizerão algumas addições para a sua perfeição; Memoria sobre o emprego do assucar combinado com a polvora; e Noticia acerca de varios carros de transporte, e particularmente do que os francezes chamão Haquet, invenção do célebre Pascal. In: $O$ Patriota..., na seqüência: 2(3): 49-51, set. 1813; (2): 99-104, fev. 1813; (1): 9-23, jan. 1813 e (4): 68-80, abr./1813.
}

(3); Comércio (3); Correspondências (5); Estatística (10); Geografia (4); História (17); Hydraulica (2); Leis (3); Litteratura-Eloqüência (1); Litteratura-Gramática (7); Litteratura - Poesia/Prosa (77); Matemática (1); Medicina (7); Mineralogia (7); Navegação e Hidrografia (8); Necrológicos (4); Notícias (10); Obras publicadas nesta Corte (10); Observações Meteorológicas (17); Política (55); e Topografia (12).

Embora o maior número de textos tenham sido de "Literatura" (28,5\%) e de "Política" (20,5\%), seguidos de longe por "Observações Meteorológicas" (6,3\%), "História" (6,3\%) e "Botânica e Agricultura" (5,5\%), o levantamento da quantidade de páginas por assunto exibe outra informação. "História" traz o maior número de páginas publicadas $(16,6 \%)$, seguido por "Política" $(16,1 \%)$, "Literatura" (13,7\%), "Topografia" $(9,1 \%)$, "Botânica e Agricultura" (8,9\%), e "Navegação \& Hidrografia", "Artes" e "Medicina” com, em média, 4,5\% cada das páginas publicadas. Em suma, 1/3 do que era publicado n'O Patriota relacionava-se com a política nacional e internacional e divulgava odes e poemas e cantos. $\bigcirc$ restante era ciência.

A média de páginas escritas por artigo demonstra uma radical troca de posições, excetuando-se os artigos de História, que foram publicados com cerca de 17,8 páginas. Excetuando-se a História, os artigos mais longos foram os de Topografia (13,8 p.), Geografia (11,5 p.), Medicina (11,3 p.), Eloqüência (11 p.), Botânica e Agricultura (10,8 p.), Navegação e Hidrografia (10,6 p.) e Artes (9,1 p.). Artigos longos, linguagem científica, exposição de experimentos e de observações. Assim eram os textos publicados n'O Patriota.

O Patriota teve 161 assinantes no Rio de Janeiro no primeiro semestre de 1813 e 135 no segundo semestre. Não publicou, no 6º número de 1814, a lista de Assinantes da cidade, como nos anteriores.

\section{OS ANNAES FLUMINENSES}

Após o último número d'O Patriota, em dezembro de 1814, o Brasil teria de esperar oito anos para ver surgir outro periódico semelhante. Em 1822, é publicado no Rio de Janeiro o Annaes Fluminenses de Sciencias Artes, e Litteratura Publicados por huma Sociedade Philo-Technica no Rio de Janeiro. Impresso na Typographia de Santos e Souza ("e Officina dos Annaes Fluminenses"*), tinha como dirigente José Vitorino dos Santos e Sousa (?-1852), português, matemático e autor de várias obras de matemática e física.

\footnotetext{
* Conforme verso da folha de rosto dos Annaes...
} 
Conforme Vianna (1945), foi a única revista literária do governo de dom Pedro I, sucedendo As Variedades e $O$ Patriota. Além de dirigida, era também redigida por José Vitorino dos Santos e Sousa, um dos primeiros lentes do curso matemático da Academia Real Militar (do mesmo modo que Ferreira de Araújo, o editor d'O Patriota).

A referida "Sociedade Philo-Technica" nunca chegou a funcionar, apesar de oficialmente autorizada e com renomados apoiadores, como José Bonifácio de Andrada e Silva, José Silvestre Rebelo e o Conde de Palma, que seria seu presidente. Possivelmente a Sociedade PhiloTechnica tenha sido atropelada pelas reviravoltas políticas de José Bonifácio no ano seguinte.

Abrindo os Annaes, acha-se o "Plano da Obra", longo editorial de 16 páginas, possivelmente escrito por José Bonifácio, conforme afirma Alfredo do Vale Cabral, citado por Vianna (1945). Como considera Vianna, "realmente, por seu estilo e idéias elevadas, vê-se ser de autor de nível intelectual e político superior ao do redator e impressor". *

O autor abre Plano da Obra com um convite, afirmando que o Annaes "servirá de estimulo para os Sabios, que a quizerem enriquecer com os seus conceitos". Segue explicando a conveniência do título do periódico, Annaes Fluminenses de Sciencias, Artes, e Litteratura,

por que estendendo as nossas vistas por todas as proffissoens do homem civil, estamos inteiramente convencidos, de que nessas rezumidas expressoens abrangem-se todas as aplicaçoens, que entertem a sociedade humana (PLANO DA OBRA, 1822, p.3).**

$\mathrm{Na}$ seqüência apresenta uma classificação do conhecimento. Conhecimentos que recaem nas faculdades completas seriam a Matemática, a Medicina, a Filosofia, a Economia Política, o Direito e a Legislação. Os conhecimentos eruditos ("que recahem em fontes de Erudiçam”) seriam a História, a Eloqüência, as Línguas, as Antigüidades e a Literatura. Já as Ciências, qualificadas com o nome de Artes, são a Poesia, a Pintura, a Cirurgia, a Arte Militar, a Agricultura, o Comércio, a Navegação e as Manufaturas (PLANO DA OBRA, 1822, p.3-4).

Conforme o autor afirma, compreende-se como Artes "todo o Systema de conhecimentos, que he possivel reduzir á regras invariaveis, e independentes do capricho,

\footnotetext{
* Alfredo do Vale Cabral afirma ter ouvido essa informação de Vernhagen (VIANNA, 1945, p. 103).

** Significativa parte dos textos originais dos periódicos analisados traz espaços antes de vírgulas e pontos de exclamação, e após aspas e parênteses. Preferimos manter a grafia original, como se verá nas citações no decorrer do artigo.
}

e da opiniao", e que, segundo ele, "todas as artes uteis sam tanto mais nobres, quanto mais necessarias para a mantença da sociedade" (PLANO DA OBRA, 1822, p.4). A visão utilitarista da ciência continua tão valorizada quanto se verificou nas páginas d'O Patriota, oito anos antes. Essa visão fica também demonstrada nos Annaes, quando os redatores anunciam os artigos que se seguiriam:

Como o nosso fim nam he divertir os espiritos, mas so faze-los uteis por tudo quanto interessa á prosperidade nacional; começaremos este N. por duas Memorias Politicas... (Annaes Fluminenses..., 1822, p.19).

Também é explicada, no Plano da Obra (1822, p. 7), a razão da publicação dos assuntos que levam as preferências dos redatores:

He pois fora de duvida, que os estabelecimentos relativos aos differentes ramos da industria de todo o Brasil em geral, chamam a nossa attençam, e seram descriptos debaixo do artigo das Artes. Cita a extração do ferro, a cultura do algodão e linhos vegetais, cultura da cochonilha, a fabricação de papel, o tratamento de peles e lãs, o comércio...

Como nos textos d'O Patriota, a valorização da natureza brasileira é ponto fundamental no Plano da Obra dos Annaes, assim como a relação entre o conhecimento científico e o progresso da nação:

...daremos os processos das Fabricas, para tirar proveito das materias primas, que felizmente se encontram em muita abundância por todo este vasto Continente, e que ou se desprezam, ou se nam tiram dellas as vantagens, de que sam suceptiveis.

Assim os processos de todas as Artes Metalurgicas, o conhecimento de extrahir os metais das suas matrizes; depurar, preparar, e fabricar quanto delles he suceptivel a industria humana.

O algodam, e os defferentes linhos vegetaes; (...) merecem ser desenvolvidos, assim como os methodos de os extrhir, preparar, e por em obra tudo aquillo, que forma a riqueza do reino vegetal deste rico Paiz...

A importância do desenvolvimento de conhecimento com base em referências brasileiras, ao contrário das européias, também é colocado, com as mesmas propostas de Câmara e Quintão anos antes:

* PLANO DA OBRA, 1822, respectivamente p. 7, 8 e 8. 
Á ella consagraremos nam só o primeiro lugar as Memorias sobre a Agricultura do Brasil, que tem differenças essenciaes da Europa, já pelo clima, já pela diversidade dos terrenos, e dos generos, que nelles se cultivam; mas tambem todas as descobertas, e melhoramentos, que forem applicaveis á este Paiz...*

A autoria científica já é tratada nesse texto, no momento em que o redator afirma que serão "fielmente" declarados os nomes dos autores e descobridores, respeitando-se também o anonimato conforme solicitado. ${ }^{* *}$ Os direitos autorais eram inexistentes no Brasil, e continuariam a sê-lo por muito tempo.

Também expõe a importância da ciência e de sua comunicação, oferecendo uma visão de salvação pública até, visão essa que veio se desenvolvendo desde o século XVII na Europa e que somente será descaracterizada na metade do século XX com a utilização da ciência para finalidades bélicas.

...há huma serie de verdades, que nam podem ser uteis, senam quando sam geralmente conhecidas pelo vulgo; e convencer, que os seus effeitos, que necessariamente coincidem na liberdade, e prosperidade das Naçoens, devem exactamente medir-se por esta instrucçam elementar, com que se fazem communs á todos os espiritos.

...o despotismo hia já fazendo indestructivel o seu imperio; e era a ignorancia publica, o esquecimento dos direitos do homem, e do Cidadam quem conduzia a Naçam ao precipicio, mas os Sabios nos salvaram. ${ }^{* * *}$

Esse único número dos Annaes teve 118 páginas, divididas em cinco partes: o Plano da Obra, os artigos O Banco do Brasil, Incorporação de Monte-Video e A Igreja no Brasil, ou Plano da Divizão Eccleziastica do mesmo, de Antonio Rodrigues Veloso de Oliveira, findando-se com mapas da população e o sumário.

Conforme conclui Vianna (1945, p. 105):

Com a vinheta do pelicano rasgando o peito para alimentar os filhotes, que tanto pode ser cristã como maçônica, foram encerrados os Anais Fluminenses de Ciências, Artes e Literatura, muito mais de ciências e política que artístico e literário, como se viu.

\footnotetext{
*Ibidem, p.13.

*** Ibidem, p.13.

**** Ibidem, p. 15/18.
}

Não conseguindo passar do primeiro número, naufraga o projeto de publicação de mais um periódico dedicado às ciências no Brasil.

\section{O JORNAL SCIENTIFICO E O FINAL DOS ANOS 20}

Nesses anos de reinado de dom Pedro I, muitos franceses já haviam se estabelecido no Brasil, sendo boa parte deles livreiros, tipógrafos e jornalistas. As condições políticas para o ramo melhoram significativamente. Aliadas às condições políticas, começam a surgir condições materiais para seu desenvolvimento. Desenvolve-se a arte tipográfica e importam-se novas máquinas e novas técnicas de imprimir. Ocorre, dado o momento político, intensa produção de pasquins, alguns verdadeiramente incendiários. O país fervia com a política de Pedro I. Movimentos republicanos já começavam a agitar o cenário político.

As instituições educacionais e científicas também haviam sido criadas, há pouco tempo, em algumas poucas capitais do país. Não havendo instituições fortalecidas, não se poderia desejar que a cultura científica florescesse. Assim, dependendo de fracas agremiações e desejos individuais, continuaram a surgir e desaparecer raros noticiadores e comunicadores da ciência há pouco inaugurada.

Nova tentativa de criação de um periódico científico é feita pelo mesmo redator dos Annaes, em 1826. Surge, conforme Sodré (1999, p. 99), a "quarta revista literária" brasileira: o Jornal Scientifico, Economico e Literario, ou Colleção de Peças, Memorias, Relaçoens, Viagens, Poesias e Anedoctas; Mixto de Instrucção e Recreio Acommodado a todo o genero de Leitores. Por Dous Amadores das Sciencias e das Artes, dirigido por José Vitorino dos Santos e Sousa e Filisberto Inácio Januário Cordeiro.

Pretendendo-se mensal, O Jornal Scientifico teve três números, de maio a julho de 1826, com cerca de 90 páginas cada. Trazia, além do editorial (intitulado Discurso preliminar ou Aos leitores), as seções Sciencias e Artes, Poesia e Bellas Letras, Viagens e Variedades.

No discurso preliminar publicado no primeiro número do Jornal Scientifico, os redatores não fogem ao já observado nos periódicos anteriores, quanto à visão das ciências e das artes como prelúdio ao progresso:

Nos paizes cultos, entre os povos verdadeiramente illustrados, fazem as Sciencias e as Artes vantajozissimos progressos, e d'ali, como de fócos luminosos, emitindo fulgurantes raios, propagão sua luz pela vasta 
superficie do Globo Terrestre, assim esclarecendo todo o genero de producções, tanto da Natureza como da Arte (DISCURSO PRELIMINAR, 1826, p.iii).

Na seção Sciencias e Artes deste primeiro número, os redatores informaram que o periódico compreenderia systemas e teorias da moderna Filosofia, a História Natural, a Física, a Quimica...(DISCURSO PRELIMINAR, 1826, p.viii-ix). Nesse número foram publicados os seguintes artigos: Teoria do Universo; Ensaio sobre a origem dos corpos organizados e inorganizados; Sobre o Comércio interior, canais, estradas, pontes e calçadas; Inventos modernos; Agricultura e economia rural; Química agrícola; Memória dirigida à extinta Assembléia Geral e Constituinte do Império do Brasil; Sobre o leite nutritivo da árvore-vaca; Mineralogia - Memória histórica e topográfica sobre a descoberta das minas de ferro de Sorocaba e Destilação por meio do vapor, de Frederico Luís Guilherme Vernhagen. Este último foi o único artigo assinado da seção.

Os redatores fazem uma admirável defesa do "jornalismo literário”, dando-lhe a função de promoção do enriquecimento do conhecimento humano e a difusão das luzes científicas. Mostram que estão atualizados quanto às tradições científicas européias no que se refere à comunicação do conhecimento através dos periódicos, e que seu projeto insere-se dentro de outro maior:

"Entre os oportunos meios de se promover o melhoramento dos conhecimentos humanos, he sem duvida hum dos mais faceis e vantajosos, o de se pôr em successivo uso o giro dos escritos periodicos : e com effeito, ha sido pela luminosa adopção de hum tal uso, e giro de Jornaes litterarios (sempre extensamente proficuos, quando escudados pela bem entendida liberdade da imprensa, maravilhoso vehiculo de propagação de conhecimentos uteis, que tem merecido a zelosa garantia dos Governos mais bem constituhidos, ) que nos dous ultimos passados seculos, á custa das fadigas de sabios e intrepidos Regeneradores d'antiga desprezada, abatida, e mesmo agrilhoada Filozofia, e atravez de milhares de obstaculos terriveis, oppostos por barbara Superstição, e por desmesurado Fanatismo, se diffundirão, com emissão maravilhosa, as Luzes Scientificas, sobre as Naçoens civilizadas."(DISCURSO PRELIMINAR, 1826, p. iv)

Continuam a defesa do jornalismo literário afirmando que por meio dos periódicos comunicam-se as "luzes" e os inúmeros e importantes inventos e descobertas com grande rapidez, e entre variados países. Asseguram ainda que os jornais literários são um meio fácil e cômodo de publicação das importantes utilidades que lhes podem resultar das noticias de taes descobertas, e dos melhoramentos adquiridos pelas Naçoens mais cultas e industriosas..." (DISCURSO PRELIMINAR, 1826, p. vi),

e que seria indolência, falta de zelo patriótico e fatalismo não valorizar tal meio de comunicação.

Não! Não he crivel que os Brasileiros, que de longa data se tem demonstrado dotados de bom senso, superior atilamento, summa vivacidade, elevada penetração, bom discernimento, e não vulgar aptidão para os estudos das Sciencias e das Artes, se conservem n'uma especie de desleixo, degradativo d'aquela alta estima geral a que tem superabundante jus de aspirar (DISCURSO PRELIMINAR, 1826, p. viii).

Assinam o Discurso preliminar os "dous associados Amadores das Sciencias e das Artes”, não publicando os seus nomes. Apenas deixaram, no frontispício do primeiro número, suas iniciais".

Deve-se salientar o uso do termo "periódico" feito pelos redatores do Jornal Scientifico ao redigirem um protesto no qual reclamam seus direitos de propriedade intelectual, como segue:

Por quanto a Constituição do Imperio garante o Direito de Propriedade aos Editores de Obras interessantes, nós os Redactores deste Jornal protestamos reclamar o direito que nos assístir relativamente a contrafactores; dando desde já por contrafeitos aquelles Numeros do nosso Periodico, que não forem por nós chancellados com a presente (PROTESTO, 1826, p. x).

Tentaram os proprietários ajuda oficial, não o conseguindo. E no editorial do terceiro número, informam aos leitores a impossibilidade de continuar com o projeto, dadas as dificuldades financeiras. Encerra-se, assim, mais uma tentativa de publicação periódica no Brasil.

Também vida curta teve o primeiro periódico médico do Brasil. O Propagador das Sciencias Medicas ou Annaes de Medicina Cirurgia e Pharmacia para o Imperio do Brasil e Nações Estrangeiras foi lançado no Rio de Janeiro em janeiro de 1827, mas extinguiu-se no ano seguinte. Era editado pelo médico francês radicado no Brasil JosephFrançois Xavier Sigaud (1796-1856). Essa iniciativa particular de Sigaud naufragou após seu envolvimento em uma disputa médica com José Maria Bomtempo (1774-1843), médico e político poderoso do Rio de

\footnotetext{
* Como já citado, os diretores eram José Vitorino dos Santos e Sousa e Filisberto Inácio Januário Cordeiro.
} 
Janeiro, que afastou os colaboradores do jornal. Conforme Ferreira (2004, p.98),

sem colaboração, preenchendo praticamente sozinho as páginas semanais do jornal, Sigaud ficou convencido de que somente vinculado a uma sociedade científica o empreendimento poderia dar certo.

\section{A DÉCADA DE 30}

$\mathrm{Na}$ década de 30 começam a aparecer outros "jornais literários", como os nomeou Sodré (1999). Não somente os literários, mas os pasquins incendiários, e, como novidade, periódicos de agremiações científicas. Dos chamados "literários", dois ainda poderiam ser classificados como científicos, como são denominados pelos levantamentos realizados nessa pesquisa. São A Revue Bresilienne... e O Beija-flor.

A Revue Bresilienne, ou Recueil de Morceaux originaux sur les affaires intérieures de L'empire, la politique, et sur la statisque locale: Imitations ou piéces originales de littérature, sciences et arts, publicada no Rio de Janeiro, em 1830, também teve apenas um número.

Suas 75 páginas não trouxeram um só texto sobre as artes e as ciências, embora se propusesse a tal, mas somente notícias sobre vários países e reflexões políticas. Talvez assim não permanecesse, se tivesse continuado a existir. Assinam o periódico os redatores de O Moderador, tendo sido impresso na Typographia de Gueffier e Cia.

Já O Beija-Flor elaborou oito números, entre 1830 e 1831. Com o título completo de Beija-Flor: Annaes Brasileiros de Sciencia, Politica, Litteratura, etc., etc., por huma Sociedade de Litteratos, também era impresso na Typographia de Gueffier e Cia. Tinha como redatores João d'Aboim, Joaquim Norberto de Sousa Silva e Floriano Alves da Costa.

Publicava textos noticiosos, políticos, literários e de interesse geral, como expõe em seu primeiro editorial. Mesmo assim, publicou em seu segundo número um artigo sobre o processo de cura das queimaduras. Em seu quarto número faz um balanço da imprensa brasileira, informando haver 54 periódicos publicados no Brasil, sendo 16 do Rio de Janeiro, proporcionando, ao todo, mais de 200 empregos.

O Beija-Flor também publicou temas agrícolas, ressaltando-se a publicação de dois capítulos da obra O Manual do Agricultor Brasileiro, de Carlos Augusto Taunay, nos sexto e sétimo números. Findou-se no oitavo número, no ano seguinte de seu aparecimento.
Sodré (1999) e Vianna (1945) chamam ainda a atenção para o Semanário Político, Industrial e Comercial, dandothe a classificação de a primeira revista exclusivamente econômica editada no Brasil. Publicado em 1831, no Rio de Janeiro, também teve apenas um só número. De editor desconhecido, foi impresso na Tipografia de Lessa \& Pereira e trouxe o texto "Dissertação sobre a Independência, integridade e liberdade do Império do Brasil", outro sobre a indústria e um terceiro sobre o comércio (VIANNA, 1945, p. 71-80). Conforme Sodré (1999, p. 121), o momento ainda não era propício à comunicação científica no país:

É de 1831, no Rio de Janeiro, por outro lado, o aparecimento do Semanário Político, Industrial e Comercial, que só teve um número, comprovando mais uma vez que a fase excluía a possibilidade de êxito para periódicos especializados, concedendo-a apenas aos que se afirmassem como políticos no sentido mais estrito.

A realidade sociopolítica brasileira, até a década de 30, não se mostrava propícia aos periódicos especializados. E assim, o Brasil teve de esperar mais alguns anos para que aparecessem novos periódicos a difundir a ciência brasileira. E, para que se firmassem, foi necessário que estivessem apoiados em agremiações científicas, as quais fundaram um novo jornalismo científico, a partir de então. Nesta década, foram elas, principalmente, a Sociedade Auxiliadora Nacional (com seu periódico Auxiliador da Indústria Nacional, iniciado em 1833 e publicado até 1892), o Instituto Histórico e Geográfico Brasileiro (com a Revista Trimensal de Historia e Geographia ou Jornal do Instituto Historico Geographico Brasileiro, iniciada em 1839 e publicada até hoje) e a Academia Imperial de Medicina do Rio de Janeiro (que publicou inúmeros periódicos, iniciando com o Semanario de Saude Publica, em 1831*). Essas três instituições tiveram um papel fundamental tanto na formação, quanto na comunicação da ciência no Brasil.

\section{CONSIDERAÇÕES FINAIS}

Os "jornais literários", publicados no início do século XIX, podem ser reconhecidos como os primeiros periódicos científicos brasileiros, tendo sido importantes

\footnotetext{
*Foram eles, um sucedendo ao outro, o Semanario de Saude Publica; pela Sociedade de Medicina do Rio de Janeiro, de 1831 a 1833, a Revista Medica Fluminense, de 1835 a 1841, a Revista Medica Brazileira, de 1841 a 1845, os Annaes de Medicina Brasiliense: Jornal da Academia Imperial de Medicina do Rio de Janeiro, de 1845 a 1849, os Annaes Brasilienses de Medicina: Jornal d'Academia Imperial de Medicina do Rio de Janeiro, de 1849 a 1885, e, por fim, os Annaes da Academia de Medicina do Rio de Janeiro, de 1885 a 1902 .
} 
formadores da cultura científica da época, além de espelhá-la.

Os termos utilizados para indexar tais publicações acabaram, ao longo do tempo, por ocultar esse material em meio a tantas outras publicações brasileiras. $O$ que nos remete ao fazer bibliotecário: as bases de dados utilizadas não contêm importantes informações a respeito dessas publicações, talvez até pelas denominações utilizadas na época. Muitas delas não foram indexadas como jornais de ciência, e sim como de "arte e literatura". Muitas outras publicações, indexadas como "científicas", eram divulgadoras de breves notícias científicas. Outras ainda, indexadas como periódicos de "ciência política", eram publicações de cunho político, conforme se verificou, e não de "ciência".

A publicação d'O Patriota foi uma experiência ímpar. Por menos que tenha conseguido sobreviver, é digno de nota que, entre 1813 e 1814, tenha editado 18 números, sistematicamente, sem perda de identidade e de qualidade, ainda trazendo artigos de renomados intelectuais, cujos textos eram bastantes diretos, com poucos dos "arrebiques e ornamentos" de que fala Sodré*. Nenhum outro periódico conseguiu tal façanha nos subseqüentes 20 anos.

No início do século XIX, conforme se viu, mostra-se singular a realização dos estudiosos brasileiros a editar publicações nas áreas das ciências em um país pobre, recém-saído das amarras do colonialismo agrário escravocrata e desprovido de estrutura política, administrativa, educacional e científica.

Quando a Corte portuguesa se estabeleceu no Brasil, foi, realmente, obrigada a fundar uma instituição atrás de outra, pois nada havia no país que pudesse suportar o estabelecimento do Estado português. E é com certa estranheza que, nessa situação, tenha sido fundado um jornal voltado às comunicação da ciência, com artigos de linguagem erudita e especializada, assinados por estudiosos de várias áreas das ciências. E pode-se também compreender que diante da situação nacional tenha durado apenas dois anos, sendo que iguais tentativas não obtiveram êxito até 20 anos depois. A realidade científico-institucional não proporcionou suporte a atividades dessa natureza até meados da década de 1830 .

Também os Annaes Fluminenses de Sciencias, Artes e Litteratura, Publicados por huma Sociedade Philo-Technica no

\footnotetext{
* "Essa maneira fútil, palavrosa, arrebicada, ornamental de escrever, essa superficialidade de assuntos e de finalidades, num meio agitado, atormentado, tumultuoso, como poderia despertar a atenção?" (SODRÉ, 1999, p.161-162).
}

Rio de Janeiro mostrou-se uma publicação bem estruturada nos moldes científicos da época, embora tenha naufragado no primeiro número.

Já os periódicos Jornal Scientifico, Economico e Literario e O Beija-Flor: Annaes Brasileiros de Sciencia, Politica, Litteratura não tinham os mesmos atributos. Somente publicaram textos compilados de outras publicações e, geralmente, escritos por uma única pessoa. Procuravam divulgar o conhecimento, mas sem trazer textos originais, em sua maioria.

Mas traziam, todos, em comum, o desejo de divulgar "as luzes", conforme suas próprias palavras, de difundir os fatos, as observações, as experiências e o conhecimento útil a todos os "homens ilustres". Tais periódicos, ao colocarem a que vinham, demonstravam claramente que falavam aos seus pares. Porque somente os "homens ilustres" da Corte poderiam compreendê-los, pequena ilha no mar de analfabetos que era o Brasil do século XIX, como discorrem Carvalho (1996) e Alfonso-Goldfarb, Ferraz e Figueirôa (1997).

A história do periódico científico no Brasil demonstra que a comunicação sistematizada da ciência somente ocorre de forma estável e duradoura se estiver atrelada a instituições de mesma ou semelhante finalidade, e também com certo nível de estabilidade, e não como atividades isoladas como havia sido até então. Isso é demonstrado pela existência de periódicos que começam a ser editados na década de 30, os quais foram órgãos de comunicação de sociedades científicas fundadas no Brasil a partir desse momento.

É preciso salientar, porém, que, sem exceção, todos os redatores e colaboradores dos periódicos estudados nesse trabalho diziam-se motivados pelo progresso e pelo desenvolvimento do país. Desde os primeiros números dos jornais, em seus editoriais, artigos e notícias, pôde-se notar a presença do ideário da ciência do início do século XIX, ou seja, voltar-se ao desenvolvimento e ao progresso humano mediante o aprofundamento do conhecimento científico.

\section{AGRADECIMENTOS}

A autora agradece aos avaliadores da Ciência da Informação pelos preciosos comentários e sugestões.

Artigo submetido em 29/11/2005 e aceito em 07/03/2007. 


\section{REFERÊNCIAS}

ABELHA DO ITACOLOMY. Ouro Preto: Officina Patricia de Barboza e Cia., 1824-1825.

ALFONSO_GOLDFARB, A. M.; FERRAZ, M. H. M.; FIGUEIRÔA, S. F. de M. Diffuser les sciences "dans un océan d'analphabétisme": singularités brésiliennes. In: BENSAUDE-VINCENT, B.; RASMUSSEN, A. La science populaire dans la presse et l'edition: XIX et XX siècles. Paris: CNRS, 1997. p. 225-236.

A MALAGUETA. Rio de Janeiro: Zelio Valverde, 1822-1824.

ANNAES FLUMINENSES DE SCIENCIAS, ARTES E LITTERATURA, PUBLICADOS POR HUMA SOCIEDADE PHILO-TECHNICA NO RIO DE JANEIRO. Rio de Janeiro: Typographia de Santos e Souza: Officina dos Anaes Fluminenses, 1822.

BARROS, D. B. de. Memoria sobre a plantação e fabrico do urucú. . O Patriota: jornal litterario, politico, mercantil, \&c. do Rio de Janeiro, Rio de Janeiro, n. 1, p. 34-49, jan. 1813.

Noções sobre a cultura, e fabrico do anil e analise desta materia colorante e do pastel. O Patriota: jornal litterario, politico, mercantil, \&c. do Rio de Janeiro, Rio de Janeiro, n. 2, p. 43 48, fev. 1813.

CAMARGO, A. M. de A. Dos annaes da imprensa nacional à bibliografia da Impressão Régia. In: CAMARGO, A. M. de A; MORAES, R. B. de. Bibliografia da impressão régia do Rio de Janeiro (1808-1822). São Paulo: Editora da Universidade de São Paulo: Kosmos, 1993. v. 1, p. xi-xvi..

; MORAES, R. B. de. Bibliografia da impressão régia do Rio de Janeiro (1808-1822). São Paulo: Editora da Universidade de São Paulo: Kosmos, 1993. 2 v.

CARVAlHO, J. M. de. A construção da ordem: a elite política imperial/ teatro de sombras: a política imperial. 2. ed. Rio de Janeiro: Editora UFRJ: Relume Dumará, 1996.

DISCURSO preliminar. Jornal Scientifico, Economico e Litterario ou Collecção de Varias Peças, Memorias, Relaçoens, Viagens, Poesias e Anedoctas. Mixto de Instrucção e de Recreio Accomodado a todo o Genero de Leitores, Rio de Janeiro, n. 1, p. iii-x, maio 1826.

FERRAZ, M. H. M. As ciências em Portugal e no Brasil (1772-1822): o texto conflituoso da química. São Paulo: EDUC/FAPESP, 1997.

FERREIRA, L. O. Negócio, política, ciência e vice-versa: uma história institucional do jornalismo médico brasileiro entre 1827 e 1843 . História, Ciências, Saúde, Manguinhos, n. 11, p. 93-107, 2004. Suplemento 1.

FIGUEIRÔA, S. F. M. Ciências geológicas no Brasil no século XIX. In: _ (Org.). Um olhar sobre o passado: história das ciências na América Latina. Campinas: Editora da UNICAMP: Imprensa Oficial, 2000.

FONSECA, M. R. F. da. Luzes das ciências na corte americana: observações sobre o periódico O Patriota. Anais do Museu Histórico Nacional, Rio de Janeiro, v. 31, p. 81-104, 1999.

FREITAS, M. H. de A. Origens do periodismo científico no Brasil. 2005. Dissertação (Mestrado em História da Ciência) - Pontifícia Universitária Católica de São Paulo, São Paulo, 2005.

GUIMARÃES, M. F. de A. Introducção. O Patriota: jornal litterario, politico, mercantil, \&c. do Rio de Janeiro, Rio de Janeiro, n. 1, p. iiiviii, jan. 1813.
JORNAL SCIENTIFICO, ECONOMICO E LITTERARIO OU COLLECÇÃO DE VARIAS PEÇAS, MEMORIAS, RELAÇOENS, VIAGENS, POESIAS E ANEDOCTAS. MIXTO DE INSTRUCÇÃO E DE RECREIO ACCOMODADO A TODO O GENERO DE LEITORES. Rio de Janeiro: Typographia de Torres, 1826.

MACHADO, Ubiratan. A etiqueta de livros no Brasil: subsídios para uma história das livrarias brasileiras. São Paulo: Edusp: Oficina do Livro Rubens Borba de Moraes: Imprensa Oficial do Estado de São Paulo, 2003.

MARTINS, W. História da inteligência brasileira. 2. ed. São Paulo: Cultrix: Editora da Universidade de São Paulo, 1978. v. 2, 1794-1855.

MORAES, R. B. de. A impressão régia no Rio de Janeiro. In: CAMARGO, A. M. de A; MORAES, R. B. de. Bibliografia da impressão régia do Rio de Janeiro (1808-1822). São Paulo: Editora da Universidade de São Paulo: Kosmos, 1993. v. 1, p. xvii-xxxi.

MORAIS, A. de. A astronomia no Brasil. In: AZEVEDO, F. de (Org.). As ciências no Brasil. São Paulo: Melhoramentos, [s.d.]. v. 1, p. 81-161.

NUNES, M. F. de. A universidade e a divulgação de conhecimentos científicos e úteis no Jornal de Coimbra (1812-1820). In: CONGRESSO HISTÓRIA DA UNIVERSIDADE, 7., 1990, Coimbra. Actas... Coimbra: Comissão Organizadora do Congresso História da Universidade, 1991.

O BEIJA-FLOR - ANNAES BRASILEIROS DE SCIENCIA, POLITICA, LITTERATURA, ETC. Rio de Janeiro: Typographia de Gueffier e Cia, 1830-1831. Por huma Sociedade De Litteratos.

O ESPELHO. Rio de Janeiro: Imprensa Nacional, 1821.

OLIVEIRA, J.C. A cultura cientifica e a Gazeta do Rio de Janeiro [1808-1821]. Revista da Sociedade Brasileira de História da Ciência, v. 17, p. 29-58, jan./jun. 1997.

O PATRIOTA: jornal litterario, politico, mercantil, \&c. do Rio de Janeiro. Rio de Janeiro: Impressão Régia, 1813-1814.

PLANO DA OBRA: annaes fluminenses de sciencias, artes e litteratura. Rio de Janeiro: [s.n.], 1822. t. 1, p. 3-18. Publicados Por huma Sociedade Philo-Technica no Rio de Janeiro.

PROTESTO: jornal scientifico, economico e litterario ou collecção de varias peças, memorias, relaçoens, viagens, poesias e anedoctas. mixto de instrucção e de recreio accomodado a todo o genero de leitores. Rio de Janeiro, n. 1, p. $\mathrm{x}$, maio 1826 .

QUINTÃO, J. J. da S. Memoria sobre a cochonilha e o methodo de a propagar, offerecida aos lavradores brazileiros, por hum patriota zeloso, e amante da felicidade publica. O Patriota: jornal litterario, politico, mercantil, \&c. do Rio de Janeiro, Rio de Janeiro, n. 4, p. 11-19, out. 1813. Subscrição.

REVUE BRESILIENNE, OU RECUEIL DE MORCEAUX ORIGINAUX SUR LES AFFAIRES INTÉRIEURES DE L'EMPIRE, LA POLITIQUE, ET SUR LA STATISQUE LOCALE : imitations ou piéces originales de littérature, sciences et arts. Rio de Janeiro: Typographia de Gueffier e Cia., 1830.

RIZZINI, C. O Livro, o jornal e a tipografia no Brasil: 1500-1822. São Paulo: IMESP, 1988.

SODRÉ, N.W. História da imprensa no Brasil. 4. ed. Rio de Janeiro: Mauad, 1999.

VIANNA, H. Contribuição à história da imprensa brasileira (1812-1869). Rio de Janeiro: Imprensa Nacional, 1945. 